\title{
OBITUARY
}

\section{In memoriam: Prof Christopher J Froelich (1951-2015)}

\author{
Cell Death and Differentiation (2016) 23, 3-4; doi:10.1038/cdd.2015.141
}

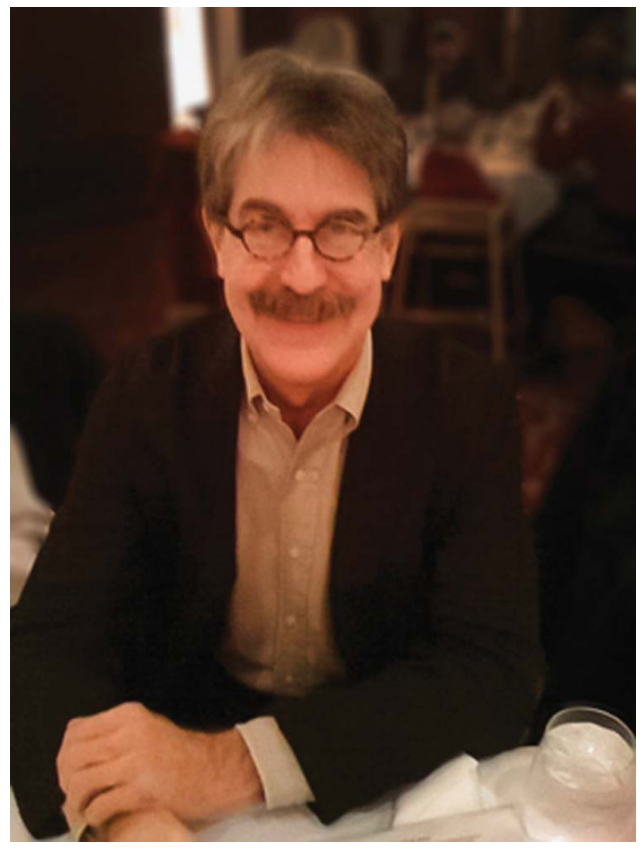

Professor Christopher J Froelich, MD, passed away peacefully on 4th April 2015 after suffering from a long-lasting illness, which he courageously fought till the end. Diagnosed with a diffuse large-cell lymphoma in February 2012, Chris underwent chemotherapy soon after. Although the lymphoma was in remission, chemotherapy had serious and debilitating side effects. Severely immunocompromised, he succumbed to fungal infections and pulmonary complications. He is survived by his wife - Melanie Terasaki, sons - Justin and Jason, daughter-in-law - Tracy, brother - Charles, sisters - Jacqueline and Jamie and beloved grandson - Hunter.

Dr. Froelich was one of the foremost experts in the field of 'Cytotoxic cell granule mediated killing'. In a prolific career spanning over three decades, he authored more than 110 scientific publications and over 20 reviews and book chapters. Chris's work was published in prestigious journals such as Science, Lancet, Immunity, Journal of Experimental Medicine, EMBO J, Journal of Cell Biology and Journal of Biological Chemistry. He was an excellent mentor to several junior scientists, postdocs and graduate students at Northwestern University and a principal investigator on two NIH RO-1 grants as well as Arthritis foundation grants. As a trained Rheumatologist, Chris also helped many patients with his astute clinical skills.

A highly original thinker, several of Chris's contributions were recognized by peers as being genuinely paradigm changing. His first major contribution was to demonstrate a novel mechanism of granzyme delivery into target cells by the pore forming protein perforin. Chris's observation that agents that disrupt endosomes (including certain viruses and endosome-disrupting bacterial toxins) could mimic perforin's actions caused a major re-think of the mechanism of perforin granzyme synergy. His second major contribution to the field was the discovery of a novel function for the granule protease - granzyme A. Chris's lab first reported that granzyme A was not strongly cytotoxic but had considerable pro-inflammatory properties. Both observations have turned out to be correct, with implications for the pathobiology of bacterial infections as well as inflammation-induced carcinogenesis.

Born in 1951 in Chicago, IL, USA to Helen and George Froelich, Chris completed his undergraduate education at the University of Colorado, Boulder, majoring in Chemistry. This was where he met his future wife and soul mate, Melanie Terasaki. He was accepted to the program at Loyola Stritch School of Medicine in Chicago and continued to pursue his research interests while completing his medical studies under the mentorship of Dr. John Robinson in the Rheumatology/ Immunology division. He graduated with honors and a member of the Alpha Omega Alpha Honor Society. Thereafter, Chris worked with Dr. Ralph Williams at the University of New Mexico in Albuquerque for his medical training (Internship, Residency in Internal Medicine; Fellowship in Rheumatology). As an intern he published an article about a patient he diagnosed with an ailment that was quite rare at the time Guillain-Barre Syndrome (Ann Intern Med, 1980; Lancet, 1981). Even in his early residency days, Chris had a gift of diagnosing rare and unusual diseases. He published several papers documenting immunologic abnormalities in autoimmune diseases (juvenile rheumatoid arthritis, systemic lupus erythematosus; Arthritis Rheumatol, 1981), culminating in his lifelong interest in studying cytotoxic mechanisms employed by natural killer (NK) and $T$ cells. He reported functional abnormalities in NK and Lymphokine-activated killer (LAK) cells of systemic lupus erythematosus patients (Clin Immunol Immunopathol, 1984; Clin Immunol Immunopathol, 1989), whereas at the same time pursuing neuro-immuno-endocrine interests observing that $\beta$-endorphins could augment cytotoxicity mediated by NK cells but not antibody-dependent cellular cytoxicity (J Immunol, 1983; Life Sci, 1984).

In 1984, Chris joined the University of Illinois at Chicago where he continued his research on NK and LAK cells and was awarded a V.A. Merit Review for his work. While at University of Illinois at Chicago, Chris and some of his colleagues also co-founded a small diagnostic company (Thera-Test Labs Inc) that manufactures in vitro kits for the diagnosis of autoimmune diseases. In 1990 Chris moved to Evanston Northwestern Healthcare, a teaching hospital for the 
Northwestern University Feinberg School of Medicine. His lab first reported an isolation schema for granzymes (Protein Express Purif, 1993) and perforin isolation (Biochem Biophys Res Commun, 1996). Once this critical landmark was reached, Chris published several papers detailing the substrates for granzyme B (J Immunol, 1993; Curr Biol, 1996; J Biol Chem, 1996; Biochem Biophys Res Commun, 1996) as well as reporting the extracellular activities of granzyme $A$ (Cell Immunol, 1996; J Immunol, 1996). Many years were spent accruing data resulting in his first paradigm-changing model where perforin and the granzymes were internalized to vesicles after which the proteases are delivered by perforinmediated endosomolysis ( $\mathrm{J} \mathrm{Biol} \mathrm{Chem,} \mathrm{1996).} \mathrm{His} \mathrm{next}$ contribution was to demonstrate that perforin and granzymes were stored inside cytotoxic granules and exocytosed as complexes with the proteoglycan, serglycin (Immunity, 2002; J Biol Chem, 2002) and that granzyme B underwent electrostatic exchange from serglycin to target cell surface proteoglycans (J Biol Chem, 2005).

Continuing on his previous work with granzyme A, Chris and his collaborators demonstrated that this major protease lacked cytotoxic activity, but rather could induce a pro-inflammatory cytokine response from human monocytes that could be blocked by a caspase-1 inhibitor (Immunity, 2008). Several follow-on hypothesis were inspired by this finding and are currently being tested to ascertain the role of granzyme $A$ in autoimmune models as well as inflammation-induced carcinogenesis models. Over the last few years, his lab was focused on the characterization of pores formed by perforin in artificial membranes and target cell plasma membranes (Mol Immunol, 2010; J Biol Chem, 2011; Plos One, 2011; PNAS USA, 2011; Cell Mol Life Sci, 2013; Trends Biochem Sci, 2014 and Cell Death Differ, 2015). As a Rheumatologist with significant clinical responsibilities, he had a remarkably successful scientific career.

Chris was the 'IT tech support' for his lab and an early adopter of technology, always preferring to be on the cutting edge. Personally, he was a very kind human being and often went out of his way to help lab colleagues in their time of need.
He would often donate his own blood to be purified for granzymes A and B. Ironically, his LAK cells exhibited the best lytic activity amongst all normal donors in the lab! An excellent collaborator, many of his collaborations spanned across continents. He very generously shared research reagents with his peers stimulating inter-disciplinary collaborations and development of new ideas.

Chris loved his family and his favorite way to spend time with them was at his 'slice of heaven' in Hayward, WI, USA. He was an avid fisherman and loved to rollerblade - he would rollerblade on the lakefront in Evanston most days in the spring, summer and fall. That is when he would put his thinking cap on, oftentimes pulling out his little notebook to jot down ideas. Chris loved fundamental research and there was rarely a time when he was not thinking about it. Forever an optimist, he believed that good science would endure and rise to the top.

We, as his near colleagues and friends lost a thoughtful, courageous, humorous and generous companion, who readily liked to communicate his wisdom, benevolence and his own vulnerability with a grain of subtle irony. The field lost a pioneer and a visionary with his passing and is poorer for it. May his soul rest in peace.

Acknowledgements. We sincerely thank Melanie Terasaki, Jane Turbov and John Skosey for their inputs.

\section{SS Metkar ${ }^{1}, J$ Pardo², G Anderluh ${ }^{3}$, G Salvesen ${ }^{4}$, JA Trapani ${ }^{5}$ and MM Simon ${ }^{6}$}

${ }^{1}$ Research and Business Development, XEME Biopharma, 7 Deerpark Drive, Suite M-1, Monmouth Junction, NJ 08852, USA; ${ }^{2}$ Department of Biochemistry and Molecular and Cell Biology, University of Zaragoza, Zaragoza, Spain; ${ }^{3}$ Laboratory for Molecular Biology and Nanobiotechnology, National Institute of Chemistry, Hajdrihova 19, Ljubljana 1000, Slovenia; ${ }^{4}$ Sanford Burnham Prebys Medical Discovery Institute, 10901N. Torrey Pines Road, La Jolla, CA 92037, USA; ${ }^{5}$ Peter MacCallum Cancer Centre, A'Beckett Street, East Melbourne 3002, Australia and ${ }^{6}$ Max-Planck-Institute of Immunobiology and Epigenetics, Freiburg, Germany E-mail: smetkar@xemebiopharma.com 